\title{
Unstable Fracture Neck of Femur in Young Adults: Management with Cannulated Cancellous Screws Augmented with Medial Buttress Plate
}

\author{
Vaidyanathan Singaravadivelu ${ }^{1}$, Ganesan Kartheesan ${ }^{2}$, Vignesh Sampathkumar ${ }^{3}$
}

\begin{abstract}
Objective: This study is to evaluate the clinical and radiological outcome of unstable fracture neck of the femur in young adults treated with three cannulated cancellous screws augmented with medial buttress plate.

Materials and methods: Fifteen patients of less than 60 years were operated from January 2017 to March 2018. Reduction was achieved by closed or open means to Garden's alignment index grade I. Internal fixation was done with three cannulated cancellous screws through mini lateral incision, and medial buttress plating was done through modified Smith-Peterson approach. All patients were mobilized from the immediate postoperative period and allowed toe-touch weight-bearing as tolerated. All patients were followed at 2 weeks, 6 weeks, 3 months, 6 months, and 12 months postoperatively.

Results: Fracture united in 14 of 15 patients. Reduction loss and backing out of cancellous screws occurred in one patient. No cases of avascular necrosis was identified at a mean follow-up of 13.7 months. No significant femoral neck shortening was observed in all united fractures.

Conclusion: Anatomical reduction by closed or open method; stable fixation with three cannulated cancellous screws augmented with medial buttress plate, increases fracture union rate compared to the historical series using closed reduction and cancellous screw fixation alone. Open reduction and medial antiglide plate fixation do not appear to increase morbidity.

Keywords: Cannulated cancellous screw fixation, Closed or open reduction, Medial buttress plate augmentation, Unstable fracture neck of femur in young adults.

Journal of Orthopedics and Joint Surgery (2019): 10.5005/jp-journals-10079-1002
\end{abstract}

\section{INTRODUCTION}

Femoral neck fractures are rare in young patients, ${ }^{1}$ which are usually caused by high-energy trauma and continue to pose challenge to the treating orthopedic surgeon in achieving the union.

In 1935, Pauwels classified femoral neck fractures according to the verticality of the fracture ${ }^{2}$ to indicate relative stability. Irrespective of the method of fixation, the risk of complications increases as the angle of fracture inclination increases. The type III Pauwels fracture pattern is associated with increased risk of fixation failure due to greater shear forces at the fracture site. The reported rate of nonunion is ranging from 16 to $59 \%$, and the avascular necrosis of the femur head is $11-86 \% .^{3-5}$

In 1964, Garden described about the common presence of posteroinferior comminution of femur neck fracture. ${ }^{6}$ This comminution and its location allows gravitational and muscular forces to act on the fracture even in the lying patient to cause retroversion at the fracture site and femoral neck shortening.

Collinge et al., in a computed tomography-based study on displaced Pauwels type III femoral neck fractures in young adults, found more than $1.5 \mathrm{~cm}$ of posteroinferior neck fragment comminution and relative deficiency in $96 \%$ cases. $^{7}$

These destabilizing morphological features of Pauwels type III fracture neck of the femur mandate anatomical reduction and stable fixation, which may not be achieved by closed reduction and cancellous screw fixation alone. Schwartsmann et al. ${ }^{8}$ macroscopically and radiographically studied the morphology of 106 femoral necks collected from patients undergoing total hip arthroplasty for femur neck fracture and showed the always existing inferomedial fracture spike of the proximal head fragment.
${ }^{1-3}$ Department of Orthopaedics, Madras Medical College, Chennai, Tamil Nadu, India

Corresponding Author: Vaidyanathan Singaravadivelu, Department of Orthopaedics, Madras Medical College, Chennai, Tamil Nadu, India, Phone: +91 9840110869, e-mail: Singortho@gmail.com

How to cite this article: Singaravadivelu V, Kartheesan G, Vignesh S. Unstable Fracture Neck of Femur in Young Adults: Management with Cannulated Cancellous Screws Augmented with Medial Buttress Plate. J Orth Joint Surg 2019;1(1):1-4.

Source of support: Nil

Conflict of interest: None

This spike if anatomically reduced by closed or open means and fixed in antiglide fashion with a contoured one-third tubular plate, as hypothesized by Mir and Collinge, might increase the strength of the parallel inverted triangular cannulated cancellous screw construct and may prevent many treatment failures. ${ }^{9}$ Kunapuli et al. conducted biomechanical analysis of 40 composite femurs and reported that Buttress plate augmentation increased failure loads on average by $83 \%$, energy absorbed to failure by $183 \%$, and construct stiffness by $35 \%{ }^{10}$

\section{Materials and Methods}

We have treated 15 patients of less than 60 years of age with Pauwels type III femoral neck fracture from January 2017 to March 2018. All were of Garden types III and IV. The mean age of patients was 
36 years (range 17-60 years). A male preponderance can be noted in the study sample ( 11 men and 4 women).

The surgery was performed after an average delay of 18 days with the range from 7 days to 5 weeks, mostly due to delayed presentation. All patients were followed at 2 weeks, 6 weeks, 3 months, 6 months, and 1 year postoperatively. Fracture union and complications were assessed by plain radiograph in anteroposterior (AP) and lateral views in all follow-ups. Union was defined as the absence of visible fracture line in both views. Nonunion was defined when clearly visible fracture line present at 1 year follow-up. To assess femoral neck shortening in horizontal and vertical plane, the injured hip's line diagram was superimposed and compared with the line diagram of contralateral uninjured hip with the AP radiograph taken at the time of confirmed fracture union (Fig. 1). Any degree of osteonecrosis from Steinberg stage 2 upward on any of the follow-up radiographs was planned to define avascular necrosis.

\section{Surgical Technique}

We wanted to achieve anatomical reduction by closed or open means. The implants used were three $6.5 \mathrm{~mm}$ partially $(16 \mathrm{~mm})$ threaded cannulated cancellous screws in inverted triangular fashion through separate mini lateral incision and contoured three-holed one-third tubular plate in antiglide fashion on the inferomedial aspect of neck of the femur to buttress at the fracture site, through modified Smith-Peterson approach (Figs 2 and 3).

Under appropriate anesthesia, patient was placed in fracture table with traction attachment. Image intensifier was used to check fracture reduction. Not more than two attempts were made to reduce the fracture by closed means by gentle traction and internal rotation of the leg. Lowell's shallow $S$ curves on both views on fluoroscopy were considered as good reduction. When fracture reduction was achieved by closed means, cannulated screw guide wires were introduced into femoral head through small incision over the lateral aspect of proximal femur. Cannulated cancellous screws implanted in inverted triangular fashion were pending final tightening. With the limb still in fracture table, the neck of the femur was exposed through modified Smith-Peterson direct anterior approach. The ascending branch of lateral femoral circumflex artery was typically found in the midportion of the incision; and by blunt dissection, an attempt was made to preserve this artery to utilize its

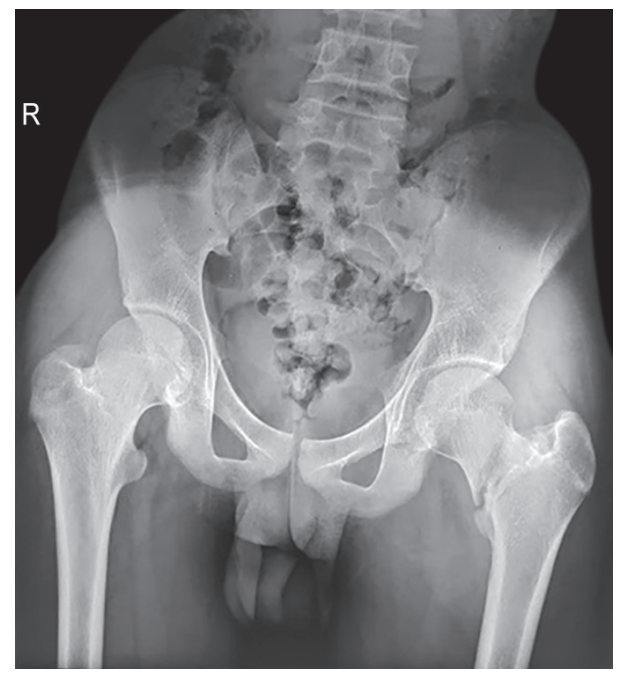

Fig. 1: Preoperative $\mathrm{X}$-ray fracture of femur neck contribution of blood supply to the femur head. The hip joint capsule was exposed by mobilizing gluteus minimus and tensor fascia laterally and the iliopsoas and rectus femoris medially. Two cobra retractors were placed, one above and one below the femoral neck, extracapsularly. The T-shaped capsulotomy was made sharp through anterior capsule, with the long limb of capsulotomy in line with the femoral neck and the other limb along the capsulolabral junction, not going too posteriorly to avoid possible damage to the medial circumflex femoral artery entry point as it provides the primary blood supply to the femur head. After evacuation of hematoma, the capsule was tagged with heavy sutures for elevation and retraction. The two cobra retractors were then repositioned inside the capsule, one above and one below the femoral neck, giving an excellent view of the entire anterior surface of femoral neck and fracture. Now the limb was freed from the fracture table and was held by an assistant with the hip in abduction and external rotation and knee in flexion, which was to elevate the capsule along the inferomedial neck toward the lesser trochanter, which was essential for the placement of medial buttress plate. The undercontoured three-holed one-third tubular plate was used. The proximal hole portion of the plate was used to buttress the head fragment, and the screw was not placed in this hole to avoid the drilling of the femur head. The middle hole was positioned just below the fracture spike of the head fragment, so the plate and the $3.5 \mathrm{~mm}$ cortical screw through middle hole create an axilla at the apex of the fracture and the proximal fragment reduces into the axilla. Distal hole was filled with another $3.5 \mathrm{~mm}$ cortical screw. This antiglide fashioning of the plate and screw buttresses and prevents the tendency of varus displacement of the unstable fracture neck of the femur and also achieves compression along the fracture line. Final tightening of the cannulated cancellous screws was done. Full range of hip movements was made to confirm the absence of plate impinging on the labrum. Capsule was closed. Wound was closed in layers.

When closed reduction was not achieved, the fracture was open reduced by the same approach as mentioned, K-wire joysticks were used to reduce the fracture. Multiple $\mathrm{K}$ wires were used to hold the reduction. Then the fracture was fixed with the implants as mentioned above.

Postoperatively supine abductor strengthening exercises were started early and toe-touch weight-bearing was allowed as tolerated.

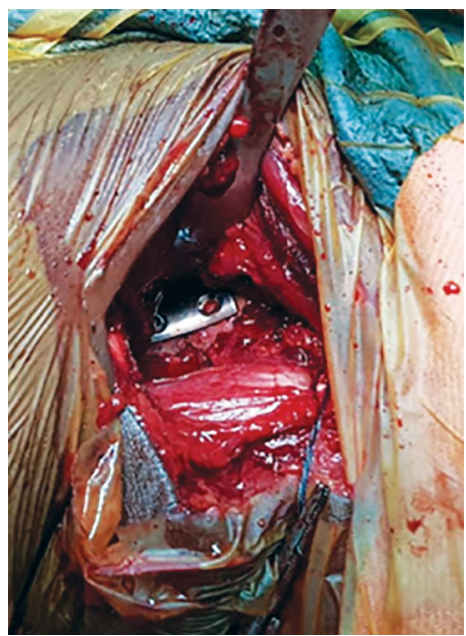

Fig. 2: Perioperative picture showing one-third tubular plate on the medial side of femur neck 


\section{Results}

Of the 15 patients who underwent this surgery, closed reduction was achieved in four patients. All these four fractures were less than 2 weeks old (from 7 days to 14 days) when operated. Remaining 11 fractures were reduced by open method, with the average delay of 23 days (range from 14 days to 35 days) (Table 1).

The mean follow-up was 13.2 months (range 12-18 months). All patients were operated by the lead author (Prof VSV). The mean operative time was 61 minutes for closed reduction cannulated cancellous screw fixation with open buttress plate fixation group (range 58-97 minutes). The mean operative time for open reduction cannulated cancellous screw fixation and antiglide plate fixation group was 90 minutes (range 63-106 minutes).

The incidence of complications related to the surgery is shown in Table 1. In one patient nonunion and cancellous screw backing out was noted at 6 months' follow-up, and implant removal and

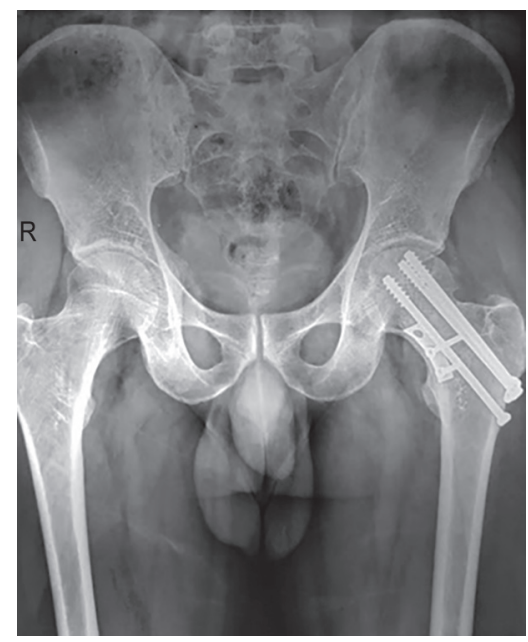

Fig. 3: Postoperative X-ray showing three inverted cannulated cancellous screws with one-third tubular antiglide late bipolar arthroplasty were done. The mean femoral neck shortening was $4 \mathrm{~mm}$ (range 2-9 mm). Two patients reported mild pain during walking till 3 months' follow-up.

In all, 93\% union rate was achieved in our series. The average time taken for radiological union was 188 days, ranging from 90 to 330 days. No avascular necrosis was reported in any of the nine patients at the time of final follow-up.

\section{Discussion}

Femoral neck fractures in the young adult is a high-risk injury due to its potential for significant complications. The timing of operative intervention, the method of achieving the anatomical reduction (closed vs open), and the choice of the implant are debatable. In spite of lack of consensus in these issues, the existing and emerging literature support the need for an anatomical reduction and supplemental fixation to prevent complications and to maximize functional outcome.

Early fixation of fracture of the femur neck is advocated in the literature; but in our series, the average delay from injury to surgery is 15 days (from 1 week to 5 weeks).

We believed the idea of achieving union by anatomical reduction and stable fixation. The risk of avascular necrosis is usually determined at the time of the primary fracture, and unstable internal fixation works against the revascularization of femoral head. Razik et al.'s retrospective analysis of 92 patients suggests to give less importance to the time to internal fixation of intracapsular fracture neck of the femur. ${ }^{11}$

Anatomical reduction was achieved either by closed or by open means. Ghayoumi et al.'s meta-analysis revealed no significant difference in the incidence of nonunion, avascular necrosis, or total complications between the closed and open reduction methods. ${ }^{12}$ The modified Smith-Peterson anterior approach enables direct visualization and manipulation of the fracture fragment for exact anatomical reduction. In addition, opening the fracture for either reduction or fixation evacuates fracture hematoma, and this may reduce joint pressure and risk of avascular necrosis of the femur head.

Table 1: Master chart

\begin{tabular}{|c|c|c|c|c|c|c|c|c|}
\hline S. no. & Patient/age & Pauwels angle & $\begin{array}{l}\text { Time since } \\
\text { injury to } \\
\text { surgery }\end{array}$ & $\begin{array}{l}\text { Open/closed } \\
\text { reduction }\end{array}$ & $\begin{array}{l}\text { Weight-bear- } \\
\text { ing started }\end{array}$ & Radiological union at & $\begin{array}{l}\text { Harris hip } \\
\text { score }\end{array}$ & $\begin{array}{l}\text { Duration of } \\
\text { follow-up }\end{array}$ \\
\hline 1 & Patient $1-17 / \mathrm{F}$ & 60 & 14 days & Closed & 5th POD & 4 months & 95.7 & 12 months \\
\hline 2 & Patient $2-17 / \mathrm{M}$ & 70 & 10 days & Open & 4th POD & 6 months & 92 & 15 months \\
\hline 3 & Patient $3-17 / M$ & 55 & 7 days & Closed & 3rd POD & 5 months & 93.7 & 12 months \\
\hline 4 & Patient 4-43/M & 55 & 14 days & Open & 4th POD & 11 months & 95 & 12 months \\
\hline 5 & Patient $5-42 / \mathrm{M}$ & 55 & 24 days & Open & 3rd POD & 7 months & 91.7 & 18 months \\
\hline 6 & Patient $6-28 / \mathrm{M}$ & 45 & 14 days & Closed & 3rd POD & 3 months & 95.8 & 12 months \\
\hline 7 & Patient 7-35/M & 50 & 21 days & Open & 5th POD & 7 months & 93.1 & 14 months \\
\hline 8 & Patient $8-45 / F$ & 55 & 14 days & Open & 3rd POD & 5 months & 79.7 & 12 months \\
\hline 9 & Patient $9-45 / \mathrm{M}$ & 50 & 12 days & Closed & 5th POD & 6 months & 78.2 & 14 months \\
\hline 10 & Patient $10-60 / F$ & 55 & 35 days & Open & 5th POD & $\begin{array}{l}\text { Nonunion implant exit/ } \\
\text { hemiarthroplasty }\end{array}$ & 79.6 & 16 months \\
\hline 11 & Patient $11-50 / \mathrm{F}$ & 55 & 28 days & Open & 4th POD & 8 months & 82 & 14 months \\
\hline 12 & Patient $12-45 / \mathrm{M}$ & 60 & 7 days & Open & 4th POD & 6 months & 91 & 12 months \\
\hline 13 & Patient $13-32 / \mathrm{M}$ & 50 & 7 days & Open & 5th POD & 5 months & 92.7 & 12 months \\
\hline 14 & Patient $14-40 / \mathrm{M}$ & 55 & 10 days & Open & 4th POD & 7 months & 90 & 12 months \\
\hline 15 & Patient $15-29 / \mathrm{M}$ & 65 & 8 days & Open & 5th POD & 8 months & 95 & 12 months \\
\hline
\end{tabular}

POD, postoperative day 
We used three $6.5 \mathrm{~mm}$ partially threaded $(16 \mathrm{~mm})$ cannulated cancellous screws in inverted triangular fashion. First the inferior screw was positioned along the inferior cortex in the AP projection and centrally on the lateral projection to resist inferior displacement and varus. Then the posterior screw was positioned along the posterior cortex, centrally in AP projection and posteriorly in lateral projection, to resist posterior displacement and retroversion of the femoral neck. The final screw was placed anteriorly on the lateral view and centrally on the AP view, to function as a tension band, resisting retroversion of the femoral neck.

To increase stability of the unstable femur neck fracture, we used medial buttress plate in antiglide fashion; this resists vertical shear forces and converts it into compression forces.

In our small series of patients with the short-time follow-up, there is no increased complications related to the antiglide plate augmentation. The union rate is better than the best results in traditional methods. ${ }^{13}$

In a similar, unrelated study of 28 patients, Ye et al. demonstrated similar results. ${ }^{14}$

Since this study is a small series of patients and of short-time follow-up, our results may be confirmed with a large multicenter series and long-time follow-up.

\section{Conclusion}

Vertically unstable femoral neck fractures in young adults are challenging, with a relatively high failure rate. Anatomical reduction and adequate stable fixation are required for fracture union. Closed or open anatomical reduction, cannulated cancellous screw fixation augmented with medial buttress plate would be the most beneficial option in these fractures. Larger randomized trials comparing this combination fixation strategy with traditional fixation methods would be essential to understand the optimal fixation method.

\section{References}

1. Robinson CM, Court-Brown CM, McQueen MM, et al. Hip fractures in adults younger than 50 years of age, epidemiology and results. Clin Orthop Relat Res 1995;312:238-246.
2. Pauwels F. Der Schenkelhalsbruch: Elin Mechanisches problem. Stuttgart: Ferdinand Enke Verlag; 1935.

3. Dedrick DK, Mackenzie JR, Burney RF. Complications of femoral neck fractures in young adults. J Trauma 1986;26(10):932-937. DOI: 10.1097/00005373-198610000-00013.

4. Kofoed H. Femoral neck fractures in young adults. Injury 1982;14(2):146-150. DOI: 10.1016/0020-1383(82)90049-3.

5. Liporace $F$, Gaines $R$, Collinge $C$, et al. Results of internal fixation of Pauwels type 3 vertical femoral neck fractures. J Bone Joint Surg Am 2008;90(8):1654-1659. DOI: 10.2106/JBJS.G.01353.

6. Garden RS. Stability and union in sub capital fractures of the femur. J Bone Joint Surg Br 1964;46:630-647. DOI: 10.1302/0301620X.46B4.630.

7. Collinge CA, Mir H, Reddix R. Fracture morphology of high shear angle "vertical" femoral neck fractures in young adult patients. J Orthop Trauma 2014;28(5):270-275. DOI: 10.1097/BOT. 0000000000000014.

8. Schwartsmann CR, de Oliveira GK, de Oliveira RK, et al. The real fracture of femoral neck. Acta Ortop Bras 2000;8(3):108-111. DOI: 10.1590/S1413-78522000000300002.

9. Mir $\mathrm{H}$, Collinge $\mathrm{C}$. Application of a medial buttress plate may prevent many treatment failures seen after fixation of vertical femoral neck fractures in young adults. Med Hypotheses 2015;84(5):429-433. DOI: 10.1016/j.mehy.2015.01.029.

10. Kunapuli SC, Schramski MJ, Lee AS, et al. Bio mechanical analysis of augmented plate fixation for the treatment of vertical shear femoral neck fractures. J Orthop Trauma 2015;29(3):144-150. DOI: 10.1097/ BOT.0000000000000205.

11. Razik F, Alexopoulos AS, El-Osta B, et al. Time to internal fixation of femoral neck fractures in patients under sixty years - Does this matter in the development of osteonecrosis of femoral head. Int Orthop 2012;36(10):2127-2132. DOI: 10.1007/s00264-012-1619-1.

12. Ghayoumi P, Kandemir U, Morshed S. Evidence based update: open versus closed reduction. Injury 2015;46(3):467-473. DOI: 10.1016/ j.injury.2014.10.011.

13. Slobogean GP, Sprague SA, Scott T, et al. Complications following young femoral neck fractures. Injury 2015;46(3):484-491. DOI: 10.1016/j.injury.2014.10.010.

14. Ye $\mathrm{Y}$, Chen $\mathrm{K}$, Tian $\mathrm{K}$, et al. Medial buttress plate augmentation of cannulated screw fixation in vertically unstable femoral neck fractures. Injury 2017;48(10):2189-2193. DOI: 10.1016/j.injury.2017.08.017. 